\title{
The sigma-1 antagonist BMY-14802 inhibits L-DOPA-induced abnormal involuntary movements by a WAY-100635-sensitive mechanism
}

Melanie A. Paquette $\cdot$ Katherine Foley •

Elizabeth G. Brudney • Charles K. Meshul •

Steven W. Johnson • S. Paul Berger

Published online: 1 April 2009

(C) Springer-Verlag 2009

\section{Erratum to: Psychopharmacology}

$$
\text { DOI 10.1007/s00213-009-1505-8 }
$$

The original version of this article unfortunately contained 2 mistakes. The presentation of Figs. 2 and 3 were incorrect. The corrected figures are given below.

The online version of the original article can be found at doi:http://dx. doi.org/10.1007/s00213-009-1505-8.

M. A. Paquette $\cdot$ C. K. Meshul · S. P. Berger

Department of Behavioral Neuroscience,

Oregon Health and Science University,

Portland, OR 97239, USA

M. A. Paquette $\cdot$ S. W. Johnson

Department of Neurology, Oregon Health and Science University,

Portland, OR 97239, USA

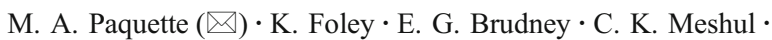

S. W. Johnson $\cdot$ S. P. Berger

Department of Veterans Affairs Medical Center,

3710 SW US Veterans Hospital Road, Mail Code R\&D 64,

Portland, OR 97239, USA

e-mail: paquette@ohsu.edu 
Fig. 2 a Relative to vehicle, BMY-14802 suppressed AIM, while WAY-100635 $(0.5 \mathrm{mg} / \mathrm{kg})$ slightly but significantly

increased AIM over the 3-h test session. WAY-100635 prevented BMY-14802's AIM-suppressing effect at $0.5 \mathrm{mg} / \mathrm{kg}$, but not $0.1 \mathrm{mg} / \mathrm{kg}$. b In the first hour of the test, BMY-14802 suppressed AIM relative to vehicle, while WAY-100635 $(0.1-0.5 \mathrm{mg} / \mathrm{kg})$ had no effect. BMY-14802's AIM-suppressing effect was prevented by WAY-100635 at $0.5 \mathrm{mg} / \mathrm{kg}$, but not $0.1 \mathrm{mg} / \mathrm{kg}$. c-f Effects on the limb, axial, and oral subscales, as well as on L-DOPA-induced rotation were similar to the summed AIM score (compare to panel a). Test compounds were administered i.p. $30 \mathrm{~min}$ prior to L-DOPA at $1 \mathrm{ml} / 100$ gm body weight. ${ }^{*} \mathrm{p}<0.001$ relative to vehicle; ${ }^{+} \mathrm{p}<0.01$ relative to BMY-14802

\section{a}

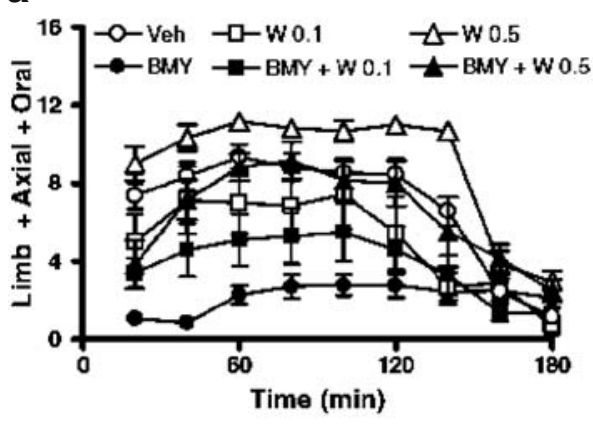

C
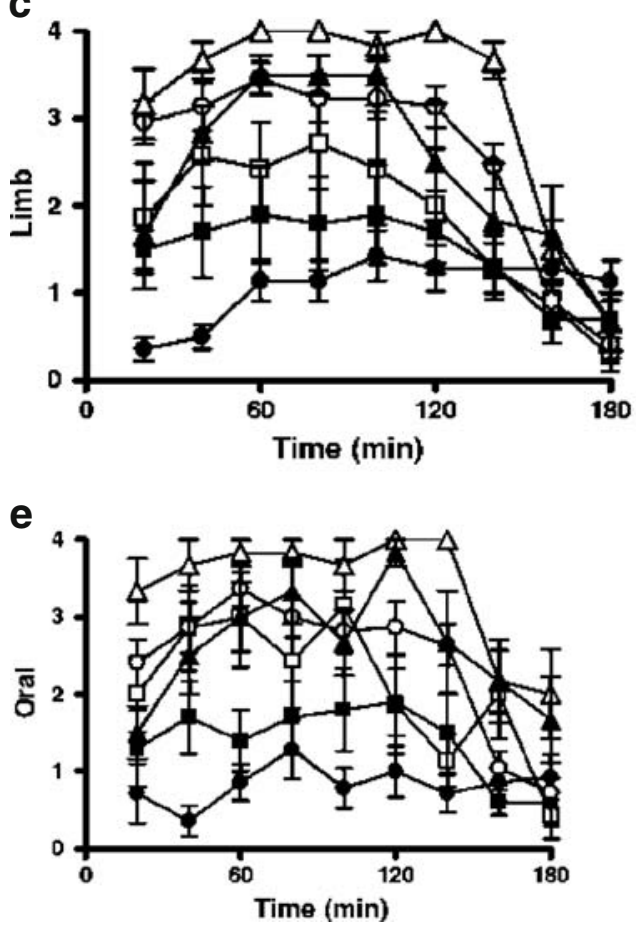

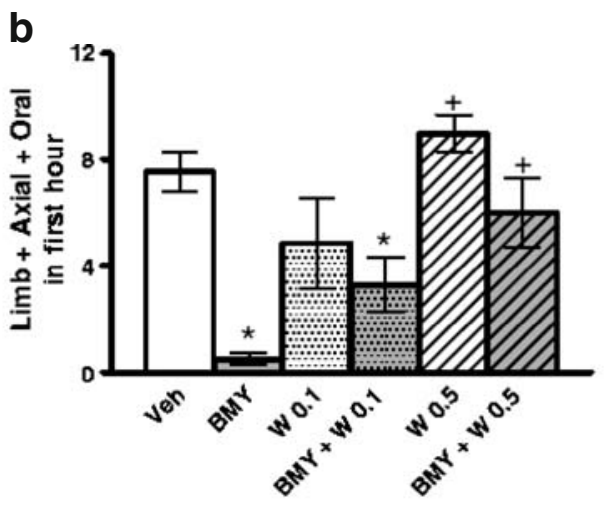

d

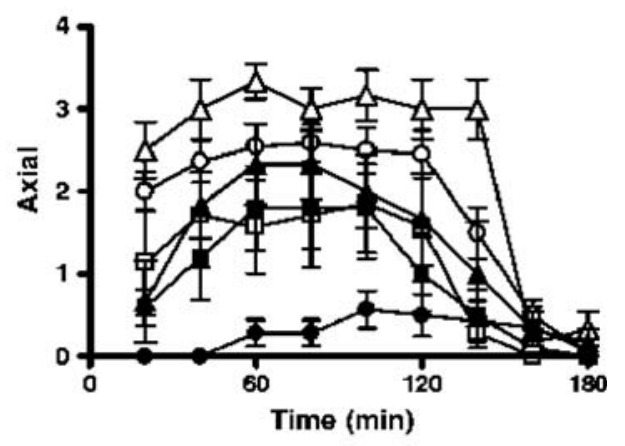

f

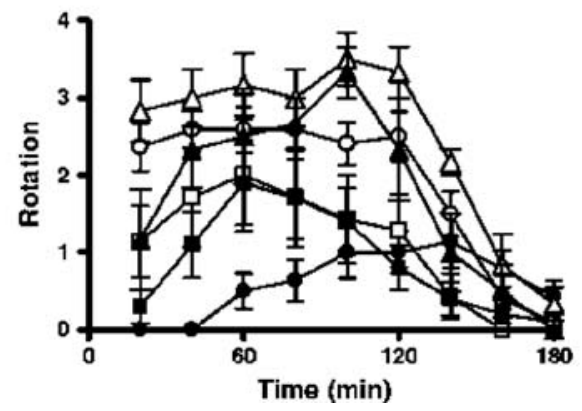


Fig. 3 a Relative to vehicle, BMY-14802 suppressed AIM, while prazosin $(0.1 \mathrm{mg} / \mathrm{kg})$ had no effect by itself or in combination with BMY-14802. b In the first hour of the test, BMY14802 suppressed AIM relative to vehicle, while prazosin had no effect by itself or in combination with BMY-14802. c-f Effects on the limb, axial, and oral subscales, as well as on L-DOPA-induced rotation were similar to the summed AIM score (compare to panel a). Test compounds were administered i.p. $30 \mathrm{~min}$ prior to L-DOPA at $1 \mathrm{ml} / 100$ gm body weight. ${ }^{*} \mathrm{p}<0.01$ relative to vehicle a

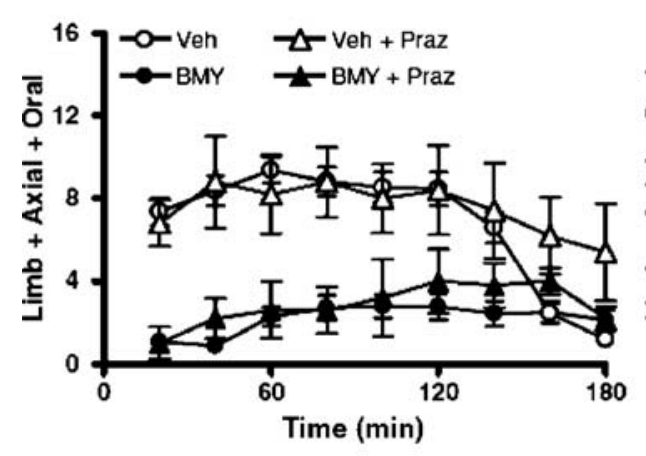

C

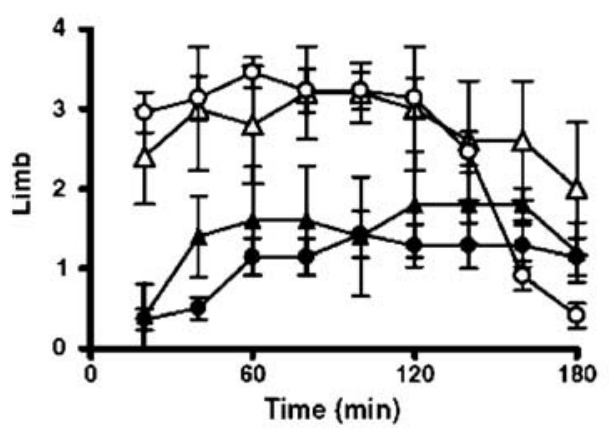

e

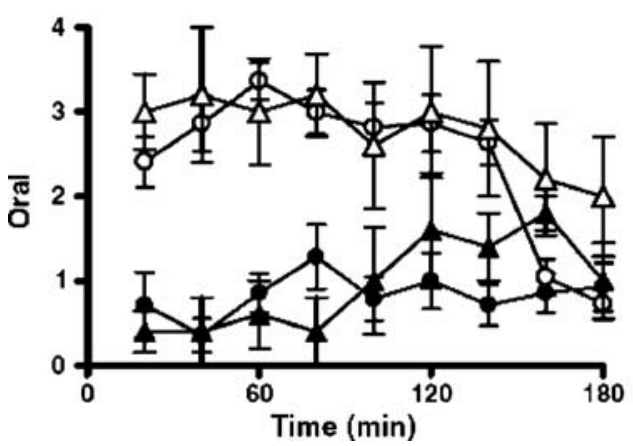

b
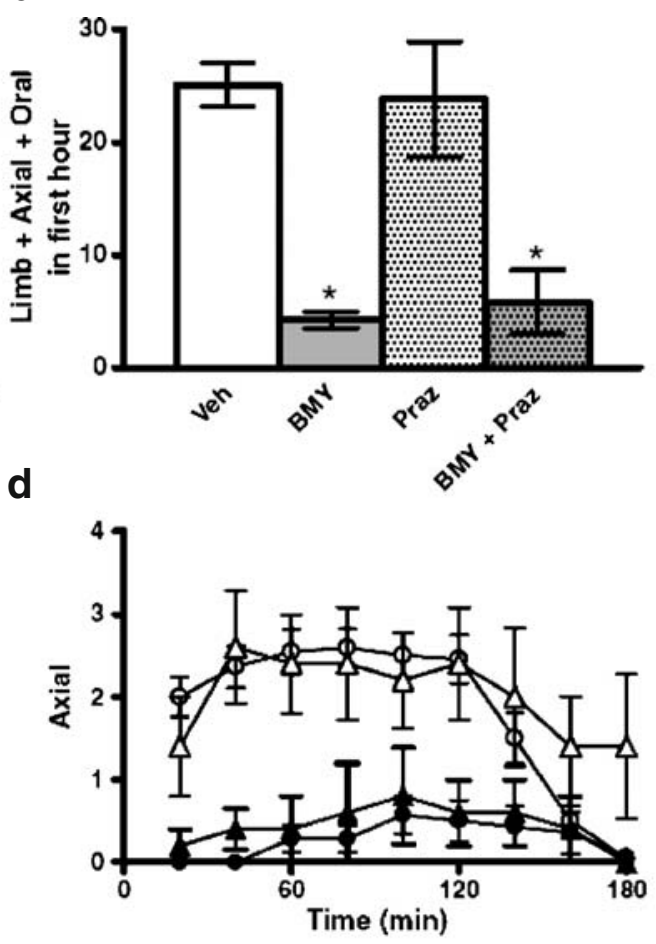

f

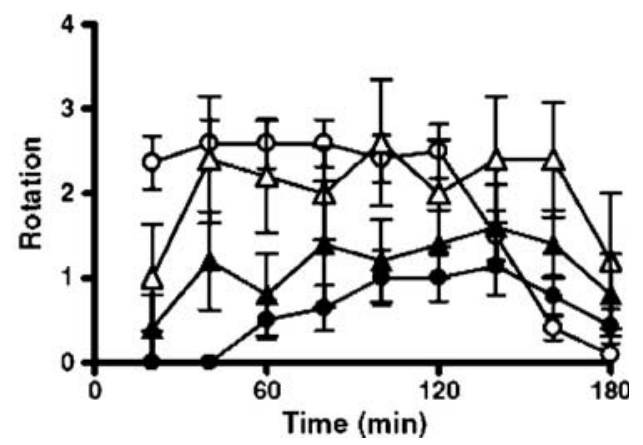

